Research Article

\title{
Study on Engineering Performance of Green Porous Sponge Ecological Concrete
}

\author{
Xiao Sun (iD) \\ School of Hydraulic and Ecology Engineering, Nanchang Institute of Technology, Nanchang 330099, China \\ Correspondence should be addressed to Xiao Sun; 512930251@qq.com
}

Received 7 April 2021; Revised 24 April 2021; Accepted 2 May 2021; Published 12 May 2021

Academic Editor: Shengwen Tang

Copyright (C) 2021 Xiao Sun. This is an open access article distributed under the Creative Commons Attribution License, which permits unrestricted use, distribution, and reproduction in any medium, provided the original work is properly cited.

\begin{abstract}
To meet the needs of sponge city construction, based on the design method of mix proportion of green porous sponge ecological concrete, the engineering performance of green porous sponge ecological concrete was studied with orthogonal experimental. The results show that the compressive strength of the specimens peaked at the $0.9 \%$ admixture of sponge; based on the optimal admixture of sponge, the compressive strength of the specimens peaked at the $12 \%$ admixture of mineral powder; compared with the ordinary concrete, the water-retaining property of green porous sponge ecological concrete is twice than ordinary, and green porous sponge ecological concrete has high permeability and low evaporation; under the same external temperature, the maximum temperature of concrete surface is lower than ordinary; and under three work conditions, the volumes of water going through the green porous sponge ecological concrete, respectively, are $1.78 \mathrm{~kg} /\left(\mathrm{s} \cdot \mathrm{m}^{2}\right), 1.47 \mathrm{~kg} /\left(\mathrm{s} \cdot \mathrm{m}^{2}\right)$, and $1.62 \mathrm{~kg} /\left(\mathrm{s} \cdot \mathrm{m}^{2}\right)$, and the value of second totally dry condition is minimum because of water blocking affection of the internal sponge. The research results will provide help for the infrastructure construction of sponge city and play an important guiding significance to promote the construction of resource-saving and environment-friendly cities.
\end{abstract}

\section{Introduction}

With the acceleration of urbanization, the problem of urban heat island effect is increasingly serious, which affects the sustainable development of human society as well as the stability of the Earth's ecosystem [1-4]. Moreover, urban expansion makes urban waterlogging disaster caused by heavy rainfall in flood season become a problem to be solved by urbanization construction $[5,6]$. The proposition of sponge city provides an effective way to solve the problem of heat island effect and urban waterlogging. Sponge city means that cities, like a sponge, have good elasticity in the face of environmental changes and natural disasters [7-10]. Rainfall water can absorb water, seep water, store water, and purify water and release and utilize the stored water when necessary. Sponge city has many advantages, such as protecting the original ecosystem of cities and well recovering the damaged hydrologic cycle $[11,12]$.

Ecological concrete has a unique structure that can be used for the construction of sponge city, so some scholars conducted numerous experiments on ecological concrete. Zhouyan [13] researched the performance of different intensities of waste concrete as recycled aggregates. The compressive strength of ecological concrete with different water absorptions of sand was tested [14]. Experimental research on ecoconcrete uses incorporating cement, fly ash, and GGBFS in [15]. The performance of ecoconcrete made from waste-derived ecocement was studied in [16]. Ecological concrete is mainly used in water conservancy revetment; considering the need for plant growth, more scholars focused on the research on plant growing concrete. Yilin and Liu $[17,18]$ expounded the application of ecological concrete in water conservancy revetment by the actual project. The green concrete plant compatibility was studied by Fujian agriculture and forestry university, the grass seed selection principles of green concrete are summarized [19]. The University of California founded that the drought resistance of grass which was planted on green concrete with $150-300 \mathrm{~mm}$ thickness is best $[20,21]$. It pointed out that the content of cement in ecological concrete 
has an important influence on the germination rate and survival rate of Bermuda grass in [22]. At the same time, pore structure is an important feature of ecological concrete. Pore structure of LHP cement-based materials was investigated by isothermal calorimetry. It is also found that the pore structure of SF-modified LHP cement concrete becomes finer and more complex as the SF dosage increases, resulting in higher fractal dimension (Ds) values [23]. Pore structure and fractal dimension (Ds) of concrete have been discussed in [24]. Pore structure affects the frost resistance and strength of concrete with different admixtures [25-28], while the length of fiber also influences the pore structure of concrete [29]. The change of pore structure influences the strength of concrete. Du [30] built an equivalent mechanical model of the concrete mesoscopic unit with porous and showed that porosity has a great influence on concrete mechanics performance. The relationship between compressive strength and porosity of concrete was obtained by the regression coefficient method [31]. Concrete strength is not only affected by the porosity but also related to the pore size distribution and pore shape $[32,33]$.

At present, in urban construction, ordinary concrete is mainly composed of four basic materials, including water, cement, sand (fine aggregate), and gravel (coarse aggregate), and this concrete does not have the function of water absorption, water storage, water seepage, and water purification and does not meet the needs of "sponge city" construction. However, green porous sponge ecological concrete is prepared by the single-graded aggregate, cement and water as well as sponge particles in a certain proportion and with a specific process. Its structure belongs to the skeleton void structure, and the void part is filled by sponge particles. Therefore, the porous sponge ecological concrete is characterized by water absorption, water retention, sound absorption, and noise reduction, but because of its large void ratio, it has a number of excellent properties, but its low strength is also a problem that needs to be solved. However, adding some high-performance polyester fiber materials (sponge) into the ecological concrete is researched in this paper, and it can reduce waterlogging of sponge city on a rainy day, but in high temperature, it can decrease the heat island with water evaporation, and meanwhile, the strength of the ecological concrete can be improved with sponge hardened after loss water.

To sum up, the proposition of green porous sponge ecological concrete combines with the concept of sponge city and green building to study its performance and make contributions to the construction and development of sponge city. Therefore, the sponge concept of green porous sponge ecological concrete enables cities to interact with nature.

\section{Materials and Method}

Based on the study of the mix ratio of green porous sponge ecological concrete, the engineering performance of green porous sponge ecological concrete is studied. The materials used by green porous sponge ecological concrete include cement, water, sandstone (coarse aggregate), sand, blast furnace granulated ore powder, and high-performance polyester fiber materials (hereinafter referred to as sponge). The optimal mix ratio is designed according to the filling theory that is shown in Table 1; then just adding the sponge directly, the optimal admixture of the sponge was determined with a series test.

However, the raw coarse aggregate is sandstone in the Jiangxi region, and its performance meets the technical specification for construction of highway cement concrete (JTG old D40-2003) specification requirements. The cement uses ordinary Portland cement. The high-performance polyester fiber materials choose the speciation sponge with good water absorption and water retention.

The grain diameter of the sandstone is chosen by laboratory test. Choose four different grain diameters, shown in Figure 1. The range of grain diameter divided into four categories, respectively, are $4.75-9.5 \mathrm{~mm}, 9.5-13.2 \mathrm{~mm}$, $13.2-16 \mathrm{~mm}$, and $16-19 \mathrm{~mm}$. Then, through the corresponding testing and calculating the air voids of the four conditions, the results are shown in Figure 2. Choose the largest void rate of the sandstone because it can accommodate more sponge particles.

The test method of compressive strength according to relevant specifications and the test method of water retention, water permeability, and evaporation of the green porous sponge ecological concrete are described in detail in the next section.

\section{Results and Discussion}

3.1. Study on Mechanical Properties of Green Porous Sponge Ecological Concrete. As a pavement material with a bearing capacity, just like ordinary concrete, its strength is an important index to characterize its mechanical properties. It is only on the basis of guaranteeing the strength that it is possible to proceed with other physical properties. The concrete material studied in this experiment is mainly used in park road and leisure square, and its strength requirement is lower than that of the highway. However, in order to improve its strength, after consulting a lot of literature, it is determined to add an appropriate amount of blast furnace granulated mineral powder in the concrete specimen, and about $10 \%$ mineral powder is added to the specimen per cubic meter.

\subsubsection{Impact of Different Sponge Particle Contents on} Compressive Strength of Concrete Specimen. In this experiment, the effects of three ages $(7 \mathrm{~d}, 14 \mathrm{~d}, 28 \mathrm{~d})$ and different sponge particle contents on the compressive strength of green porous sponge ecological concrete were studied. During the test, the arithmetic mean value of 3 specimens in each group was taken as the final measured value. If the difference between one of the measured values and the median value exceeds $15 \%$ of the median value, the median value shall be taken as the measured value. If it exceeds $15 \%$ of the median value, the test data of this group shall be invalid and tested separately. The test results are shown in Figure 3. 
TABLE 1: Designed mix ratio of green porous sponge ecological concrete.

\begin{tabular}{lccc}
\hline Type & Coarse aggregate & Cement & Water \\
\hline Amount per unit volume $\left(\mathrm{kg} / \mathrm{m}^{3}\right)$ & 1207 & 304 & 135 \\
\hline
\end{tabular}

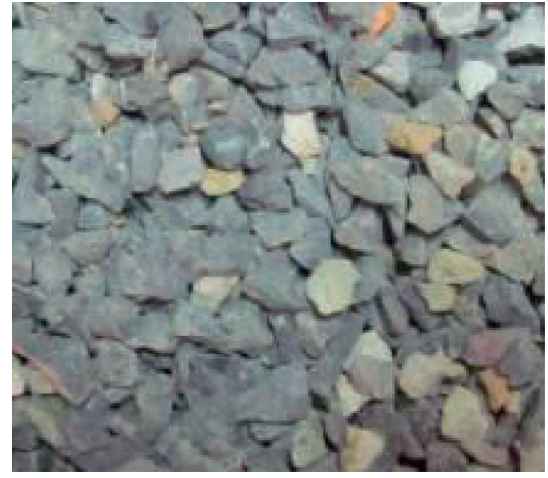

(a)



(b)

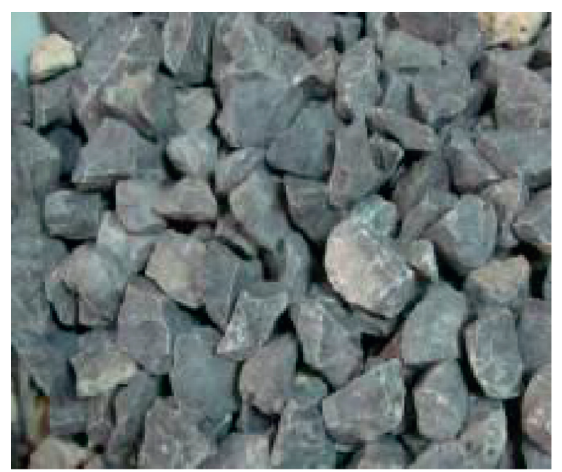

(d)

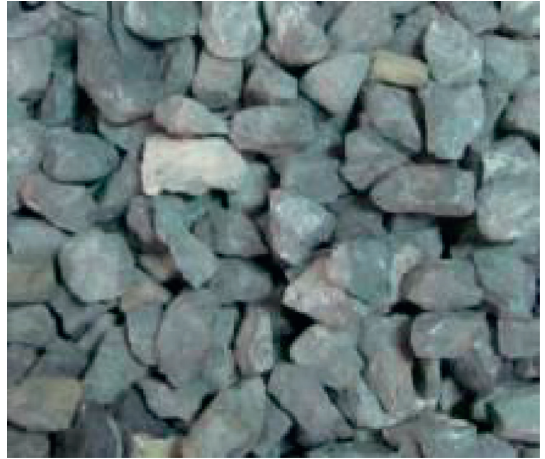

(c)

Figure 1: Different grain diameters of coarse aggregate: (a) $4.75 \mathrm{~mm}$, (b) $9.5 \mathrm{~mm}$, (c) $13.2 \mathrm{~mm}$, and (d) $16 \mathrm{~mm}$.

It can be seen from the results in the figure that there is a certain relationship between the additive amount of sponge and the compressive strength of specimen. When the amount of sponge was increased at the beginning, the compressive strength of green porous sponge ecological concrete increased with the amount of sponge, but when the amount of sponge increased to a certain extent, the compressive strength would decrease contrarily.

\subsubsection{Impact of Different Mineral Powder Contents on the} Compressive Strength of Green Porous Sponge Ecological Concrete. In this experiment, the influence of different mineral contents $(4 \%, 8 \%, 12 \%, 16 \%, 20 \%)$ on the compressive strength of porous sponge ecological concrete was studied. During the test, the arithmetic mean value of 3 specimens in each group was taken as the final measured value. The test results are shown in Figure 4.

According to the test results, there is a certain relationship between the additive amount of ore powder and the compressive strength of the specimen. When the additive amount of ore powder is in a certain degree, the compressive strength increases with the increase of the content of ore powder. When the amount of ore powder continues to increase, the compressive strength will decrease contrarily.

\subsection{Study on Water Retention and Evaporative Cooling Performance of Green Porous Sponge Ecological Concrete}

3.2.1. Study on Water Retention Performance of Green Porous Sponge Ecological Concrete. In order to study the water retention performance of green porous sponge ecological concrete, a group of porous concrete specimens of $30 \mathrm{~cm} \times 30 \mathrm{~cm} \times 10 \mathrm{~cm}$ and a group of ordinary concrete specimens were formed in this experiment for comparative study. After molding the specimens and curing for 7 days, they were put into an oven to dry for 24 hours at a temperature of $60^{\circ} \mathrm{C}$ and then soaked for 24 hours. Later, the specimens were taken out and weighed. The test results are shown in Table 2.

As can be seen from the above table, the water retention of green porous sponge ecological concrete is nearly twice that of ordinary concrete, and the water retention of porous sponge ecological concrete is relatively high.

3.2.2. Study on Cooling Performance of Green Porous Sponge Ecologic Concrete. In order to study the cooling performance of green porous sponge ecological concrete, a group of porous concrete specimens $(30 \mathrm{~cm} \times 30 \mathrm{~cm} \times 10 \mathrm{~cm})$ and a group of ordinary concrete specimens $(30 \mathrm{~cm} \times 30 \times 10 \mathrm{~cm})$ 


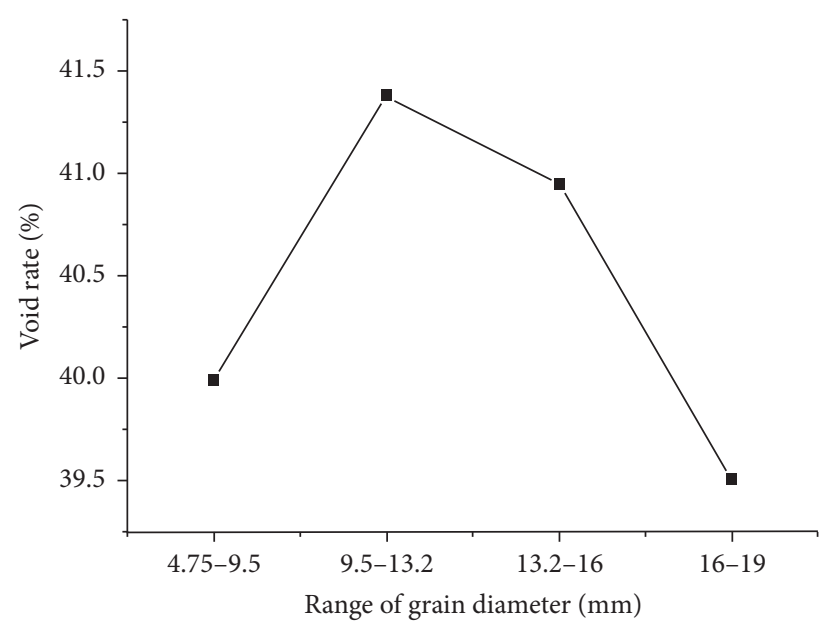

FIGURE 2: The void rate of different grain diameters of coarse aggregate.

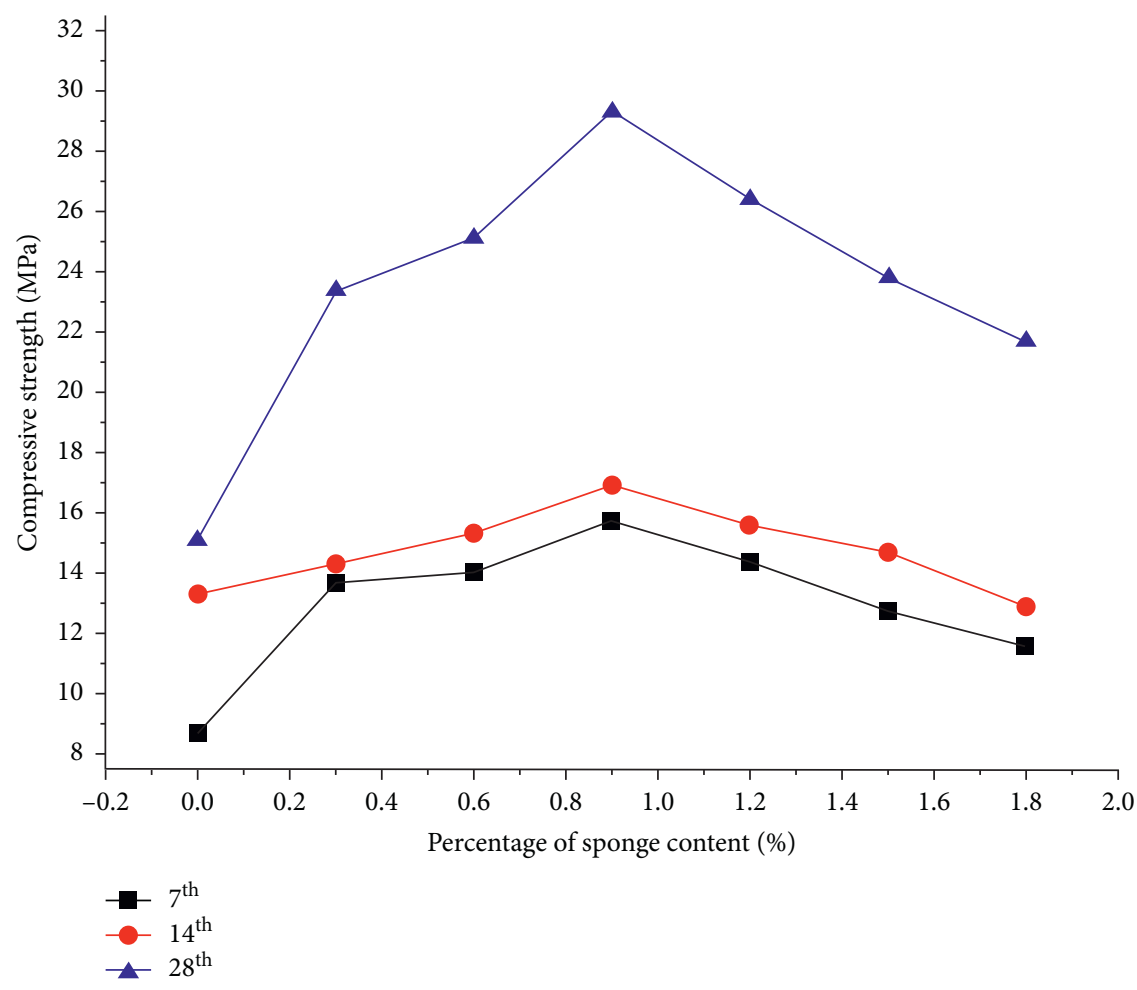

FIgURE 3: Compressive strength of concrete specimens with different sponge contents on the $7^{\text {th }}, 14^{\text {th }}$, and $28^{\text {th }}$ day.

were formed in this experiment for comparative study. After the specimen was fully filled with water, the surface temperature of the specimen was tested with an infrared thermometer under the outdoor natural condition.

In the outdoor natural state, for 5 consecutive days, the temperature was measured every 1 hour with an infrared thermometer from 10 a.m. to 4 p.m., and three groups of experimental data were measured each time and the average value was taken. The test results are shown in Figures 5 and 6.

According to the above seven figures, it can be known that the green porous sponge ecological concrete has a large number of connected voids, which can be connected with the atmosphere, and at the same time, heat can be transferred through the voids under the solar radiation. Under prolonged sunlight, the water stored in the porous sponge ecological concrete can absorb a large amount of heat, and then the water will evaporate and be lost through the void. Repeating this process in the hot summer can take away a lot of heat from the road, thus achieving the effect of cooling.

Green porous sponge ecological concrete pavement structure has a good water-retaining material sponge and heat conduction channel, which make the pavement structure be able to carry out strong self-regulation and balance of temperature, so there is usually no high- 


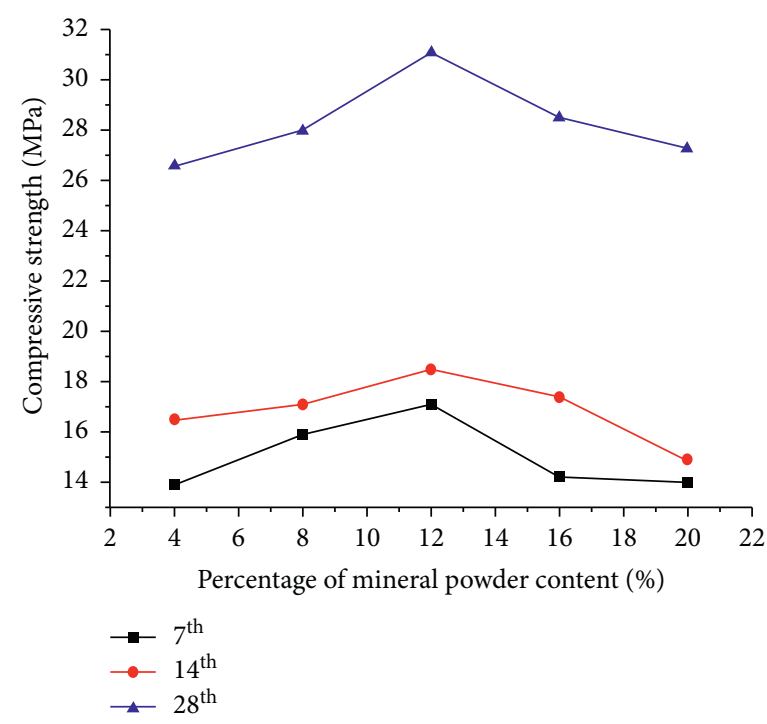

FIGURE 4: Compressive strength of concrete specimens with different mineral powder contents on the $7^{\text {th }}, 14^{\text {th }}$, and $28^{\text {th }}$ day.

TABLE 2: Water retention of concrete.

\begin{tabular}{lcccc}
\hline Type & After drying/kg & After soaking in water/kg & Soaking-drying/kg & Water absorption per unit mass \\
\hline Porous sponge ecological concrete & 14.408 & 15.034 & 0.626 & 0.0434 \\
Ordinary concrete & 21.122 & 21.588 & 0.466 & 0.0221 \\
\hline
\end{tabular}

temperature phenomenon in the pavement structure. In addition, at the same temperature, the limit high temperature of the surface temperature of green porous sponge ecological concrete is lower than that of ordinary cement concrete, so the internal temperature will also decrease accordingly.

3.3. Study on Water Permeability of Green Porous Sponge Ecological Concrete. In this section, in order to study the cooling performance of green porous sponge ecological concrete, several groups of porous concrete specimens $(30 \mathrm{~cm} \times 30 \mathrm{~cm} \times 10 \mathrm{~cm})$ and ordinary concrete specimens were formed in this experiment. Due to some restrictions, four rows of small holes were pricked on an oil bottle to carry out a water permeability test, the block was covered with transparent tape around, in order to prevent the water from flowing from the sides of the block. Then, the rainfall time was controlled as $30 \mathrm{~s}$ to $100 \mathrm{~s}$, the precipitation area was calculated as $0.0175 \mathrm{~m}^{3}$, water area was $0.06 \mathrm{~m}^{2}$, and after repeating the test several times, the permeable capacity of the two types of blocks was finally determined.

During the test, two measuring tools $\left(M_{1}\right.$ and $\left.M_{2}\right)$ were used. $M_{1}$ was to measure the water flow going through the concrete specimen. $M_{2}$ was used to measure the watering amount in the corresponding time, simulate artificial precipitation for 30-100 s, and then estimate and analyze the permeability of molded concrete specimens. The test results are shown in Table 3 and Figures 7-8.

According to Table 3 and Figures 7-8, there is an obvious ponding area on the test block of ordinary concrete, which is deep and almost has no water infiltration. After completing the precipitation test, the base surface of ordinary concrete is dry. After the completion of the test, the green porous sponge ecological concrete has no surface ponding, the permeability is faster, and the underside of the specimen is wet.

In order to further quantitatively study the water permeability of green porous sponge ecological concrete, namely, to obtain the water permeability per unit area of the porous concrete, in this test, multiple groups of porous concrete specimens were formed, which were divided into three working conditions (working condition 1: porous concrete after curing for 7 days; working condition 2: dried porous concrete after curing for 7 days; and working condition 3: saturated porous concrete after curing for 7 days). Among them, in the first and second working conditions, three groups of specimens were formed, respectively; and in the third working condition, two groups of specimens were formed.

It can be seen from the above test results that after the specimen was formed and naturally cared for 7 days, the water permeability of the specimen under working condition 1 reached the maximum, and the permeable capacity under working condition 2 was the minimum. The specimen under working condition 2 was dried. During the test, the sponge particles contained in the specimen itself would lock part of the water, so the relative permeable capacity was less than that under working conditions 1 and 3. The test results are shown in Figure 9.

3.4. Study on Evaporative Properties of Green Porous Sponge Ecological Concrete. In order to study the evaporative properties of porous concrete specimens, several groups of 


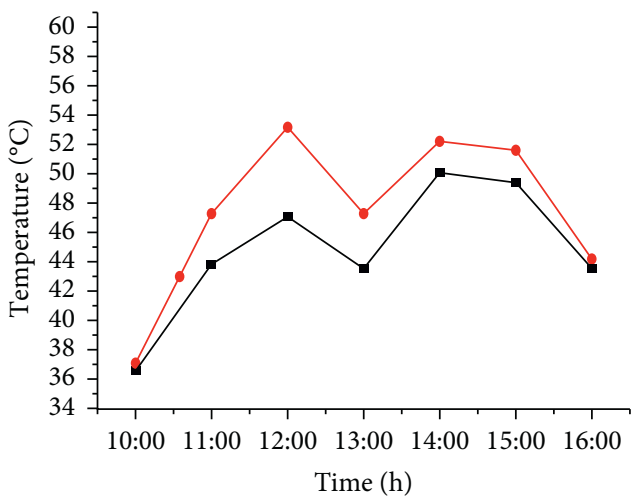

Porous sponge ecological concrete

$\rightarrow$ Ordinary concrete

(a)

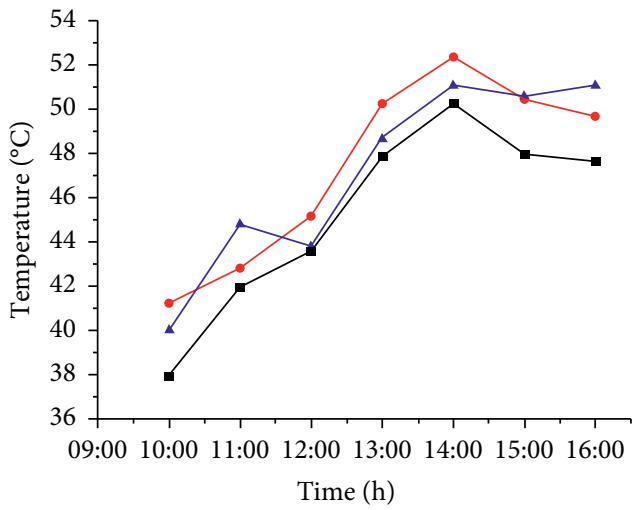

$\rightarrow$ Porous sponge ecological concrete

- Ordinary concrete

$\simeq$ Ground

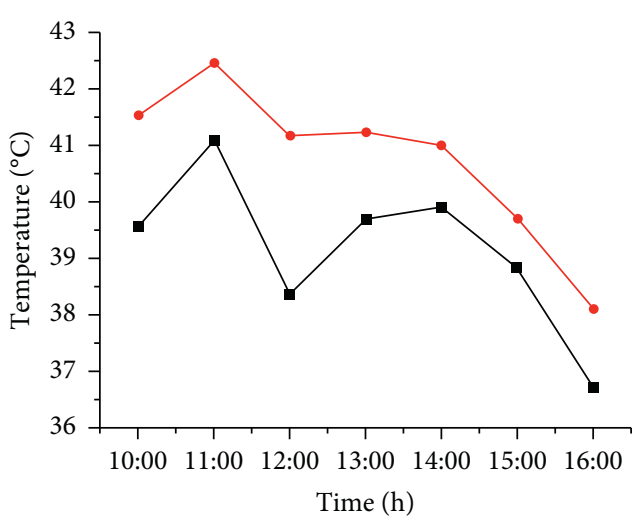

- Porous sponge ecological concrete

- Ordinary concrete

(b)

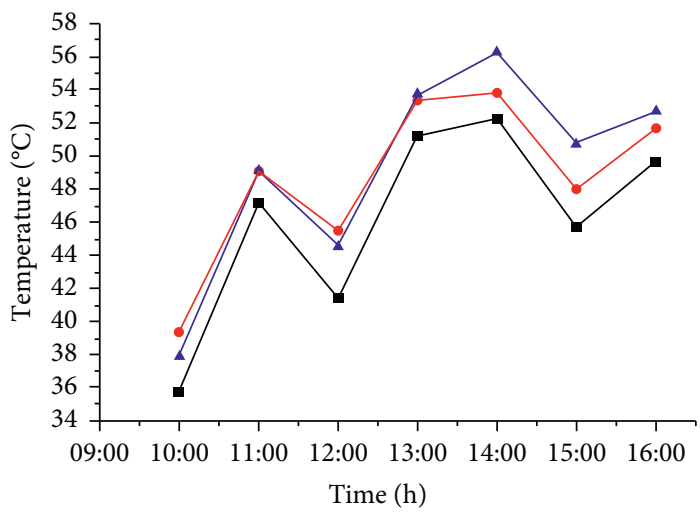

$\rightarrow$ Porous sponge ecological concrete

$\rightarrow$ Ordinary concrete

$\leftarrow$ Ground

(c)

(d)

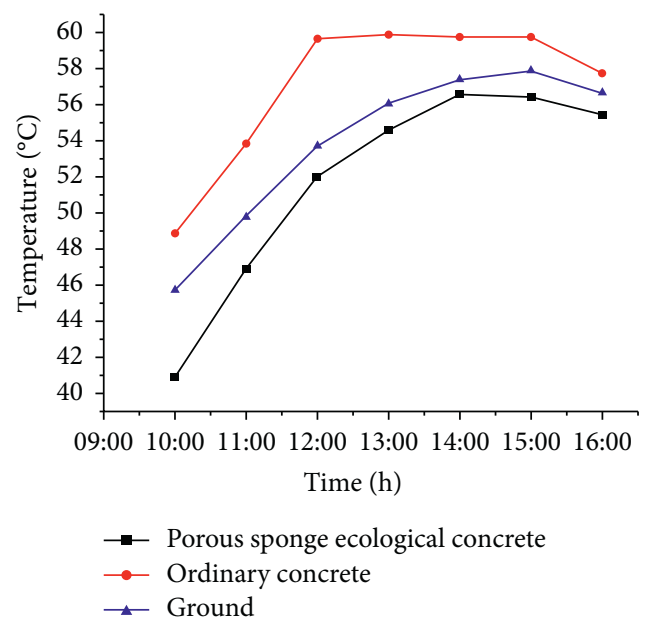

(e)

Figure 5: Temperature variation curve at different times on different days. (a) Temperature variation of porous sponge ecological concrete on the $1^{\text {st }}$ day. (b) Temperature variation of porous sponge ecological concrete on the $2^{\text {nd }}$ day. (c) Temperature variation of porous sponge ecological concrete on the $3^{\text {rd }}$ day. (d) Temperature variation of porous sponge ecological concrete on the $4^{\text {th }}$ day. (e) Temperature variation of porous sponge ecological concrete on the $5^{\text {th }}$ day. 


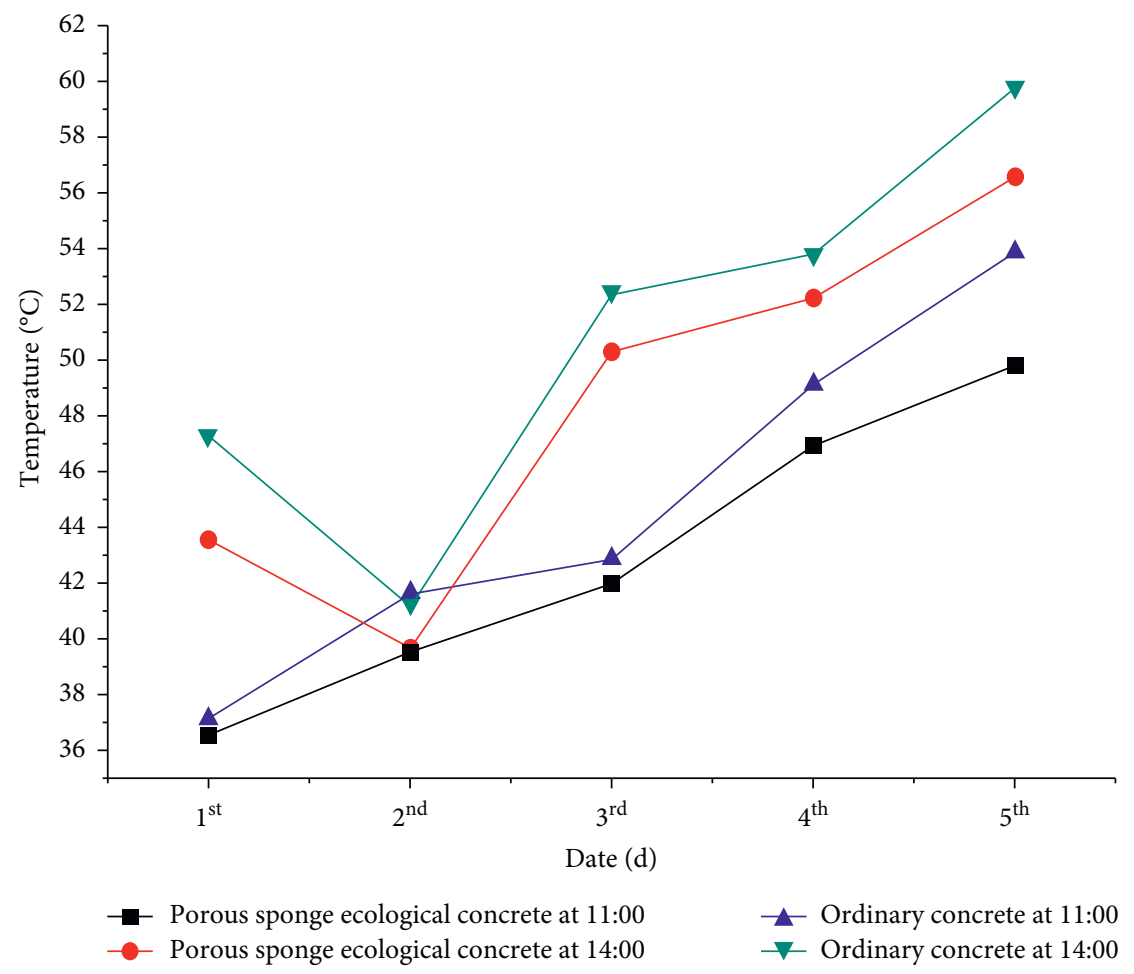

FIgURE 6: Temperature variation curve at $11: 00$ and 14:00 within 5 days.

TABLE 3: Water retention of concrete.

\begin{tabular}{lccc}
\hline Type & Watering amount $M_{1} / \mathrm{kg}$ & Permeable capacity $M_{2} / \mathrm{kg}$ & Water absorption of specimen $/ \mathrm{kg}$ \\
\hline Dried ordinary concrete & 14.644 & 0 & Specimen surface ponding $0.8 \mathrm{~cm}$ \\
Dried porous concrete & 9.116 & 9.888 & 0.378 \\
\hline
\end{tabular}

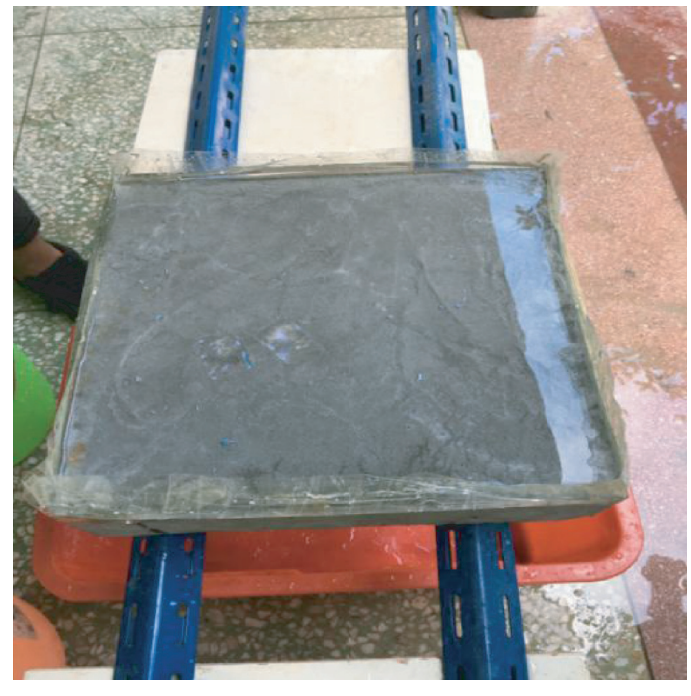

(a)

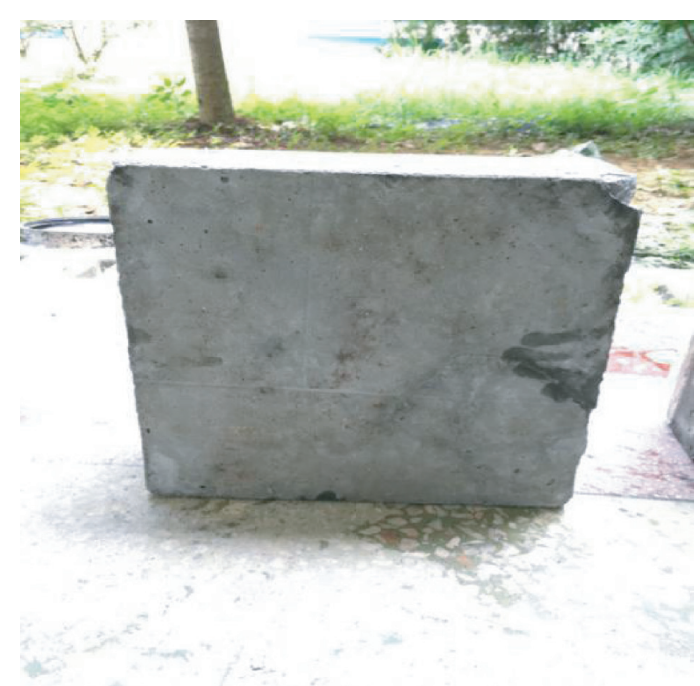

(b)

FIGURE 7: Ordinary concrete specimen after the test. (a) Specimen surface ponding is about $0.8 \mathrm{~cm}$ after the test. (b) The other side of the specimen is dry after the test. 


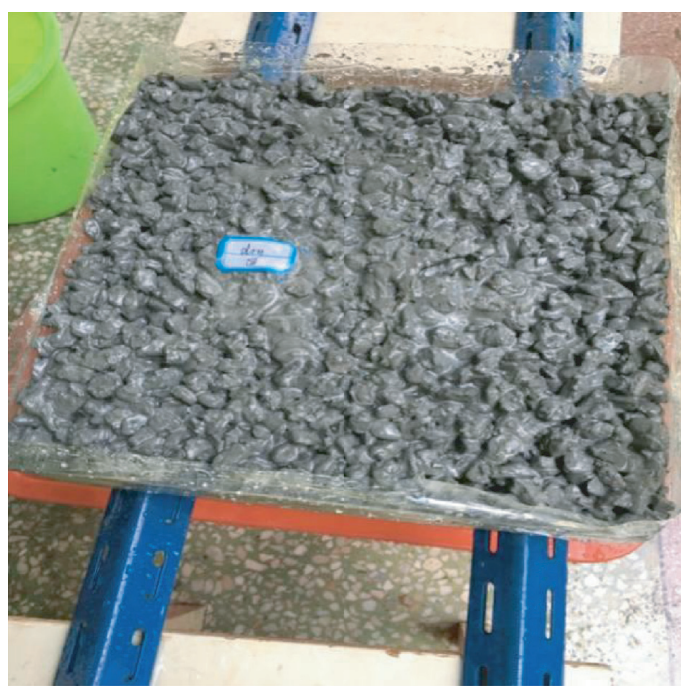

(a)

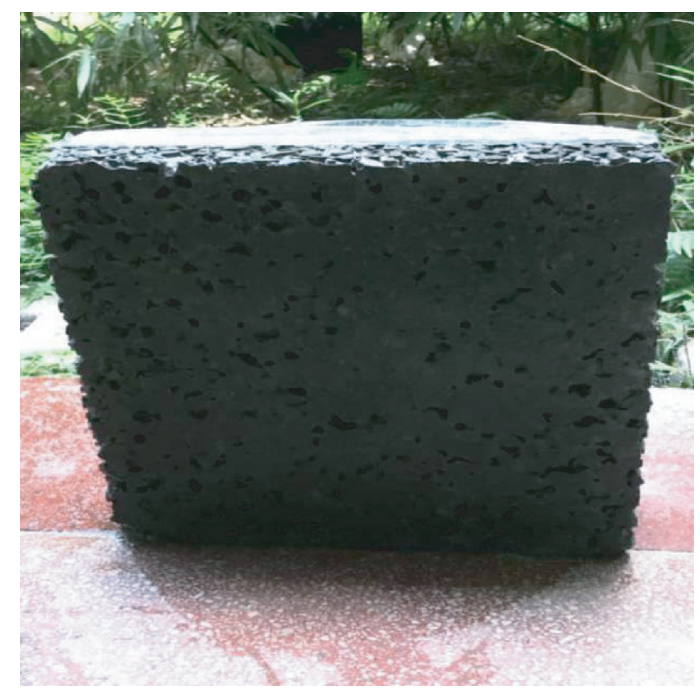

(b)

FiguRE 8: Ordinary concrete specimen after the test. (a) Specimen surface ponding is about $0.8 \mathrm{~cm}$ after the test. (b) The other side of the specimen is dry after the test.

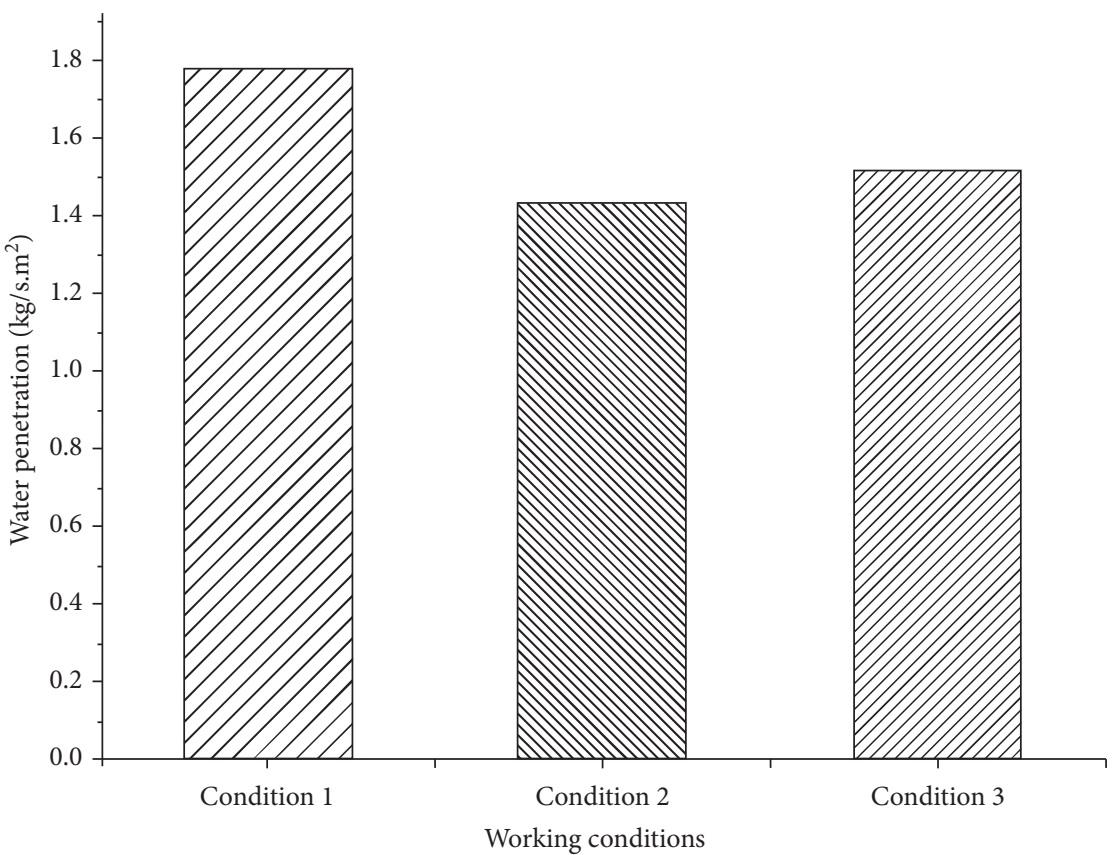

FiguRE 9: Average water permeability per unit area per unit time under different working conditions.

porous concrete specimens and ordinary concrete specimens were formed for comparative study. After the specimen was cared for for 7 days, it was put indoor to dry naturally for 24 hours, and then put into an oven to dry at $60^{\circ} \mathrm{C}$. Then, it was immersed for 12 hours and put into the even at $40^{\circ} \mathrm{C}$ and $50^{\circ} \mathrm{C}$, respectively. It was weighed before putting into the oven for 10 hours, then it was weighed again every 30 minutes, and the water loss was determined according to the mass difference. The test results are shown in Figures 10-11.
According to the test results and the relationship diagram, it can be known that after the fully immersed specimens were dried in the oven for 10 hours, the water loss evaporation capacity of green porous sponge ecological concrete was smaller than that of normal concrete at different temperatures. As the sponge particles added to the porous concrete locked part of the water and due to the continuous space structure, it also indicated that the water retention performance of porous concrete was relatively good. So, it can reduce the temperature of the road in hot weather. 


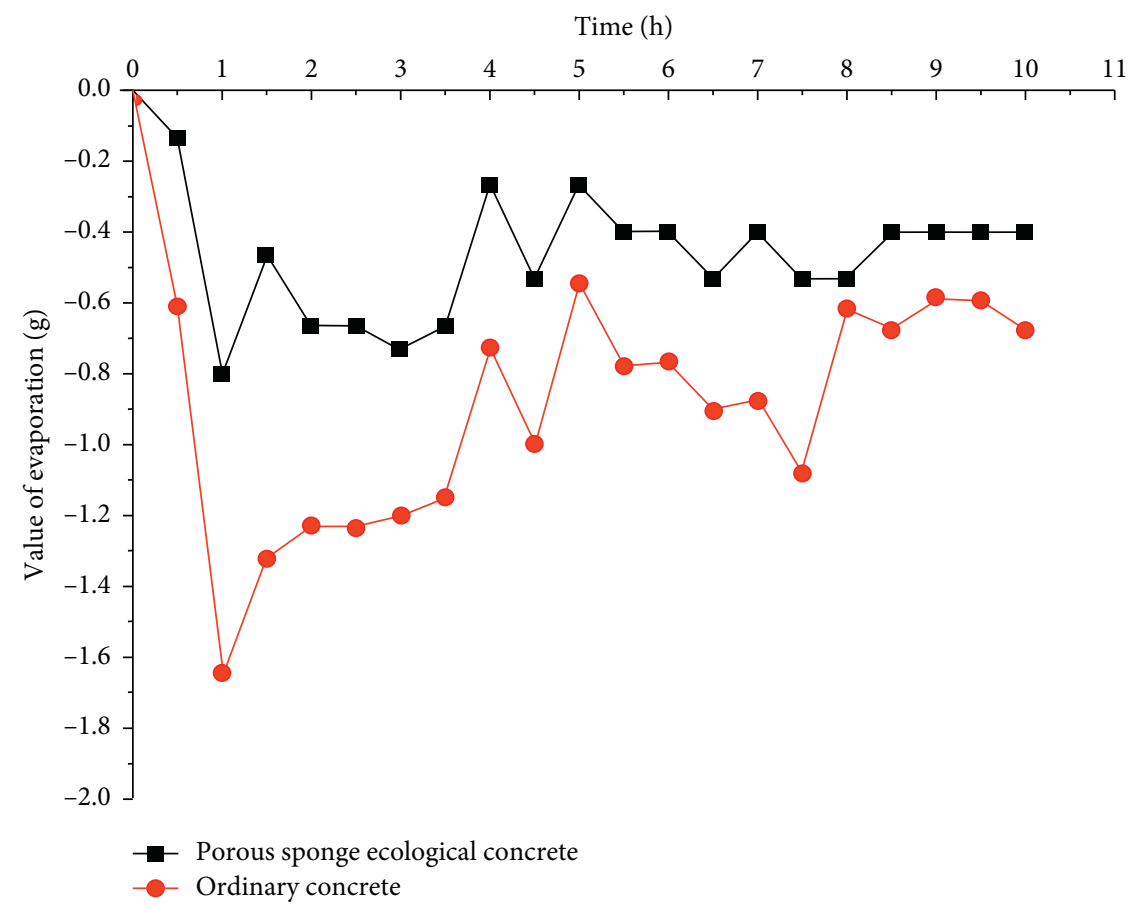

FIgURE 10: Average water evaporation per unit mass per unit time under different working conditions $\left(40^{\circ} \mathrm{C}\right)$.

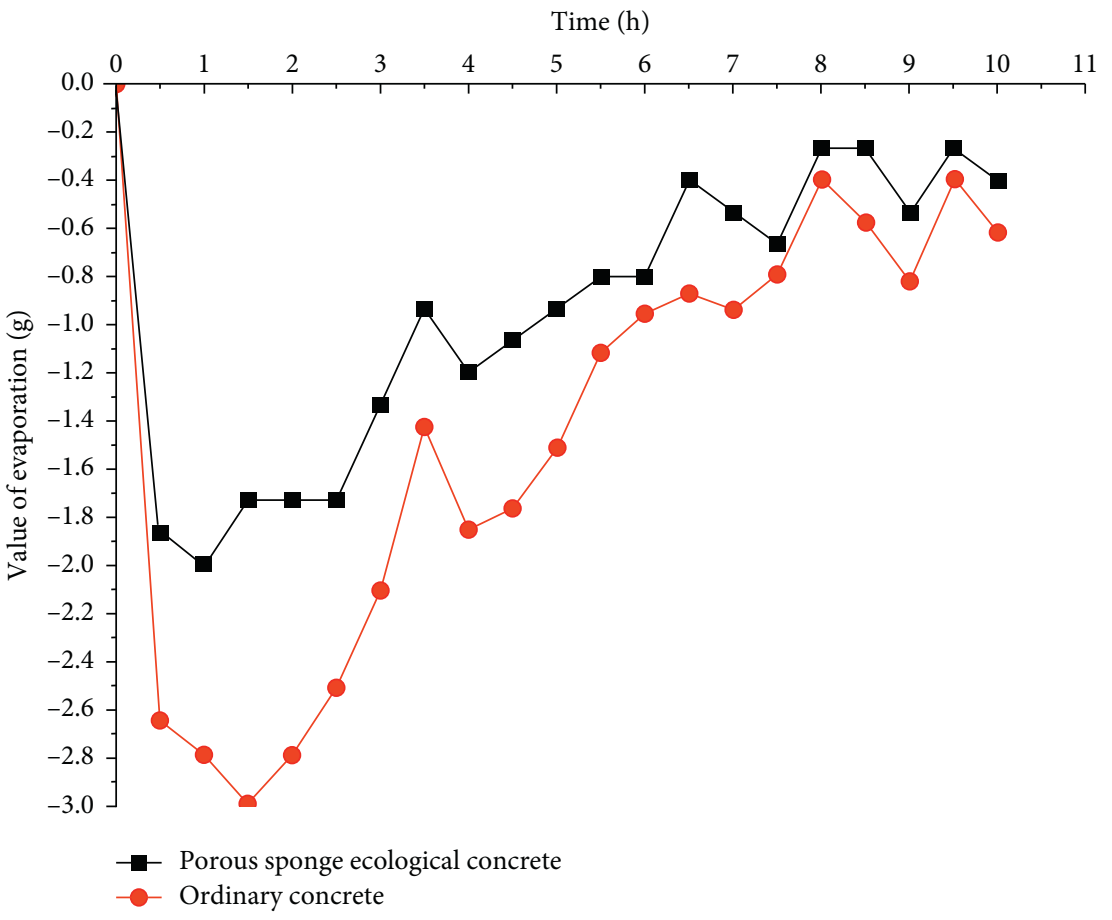

FIgURE 11: Average water evaporation per unit mass per unit time under different working conditions $\left(50^{\circ} \mathrm{C}\right)$.

3.5. Economy and Environmental Protection of Green Porous Sponge Ecological Concrete. In order to study the evaporative properties of porous concrete specimens, several groups of porous concrete specimens, one of the advantages of green porous sponge ecological concrete is that it uses less cement, so as to reduce $\mathrm{CO}_{2}$ emissions in the air. In order to quantitatively study its economic and environmental performance, a park footpath with a length of $50 \mathrm{~m}$, a width of $1 \mathrm{~m}$, and a pavement thickness of $0.1 \mathrm{~m}$ is built for comparative study.

According to relevant information, it can be known that the $\mathrm{CO}_{2}$ emission of $1 \mathrm{t}$ cement is $653.38 \mathrm{~kg}$ [4]. The cost of $1 \mathrm{t}$ ordinary cement is 635.5 yuan. Therefore, a comparative calculation is carried out. Table 4 shows the calculation results: 
TABle 4: Economic and environmental protection of concrete.

\begin{tabular}{lcc}
\hline Type & Cement content/t & $\mathrm{CO}_{2} \mathrm{emissions} / \mathrm{kg}$ \\
\hline Ordinary concrete & 1.99 & 1300.23 \\
Green porous sponge ecological concrete & 1.52 & 993.14 \\
\hline
\end{tabular}

It can be seen from the calculation results that, in comparison, $0.47 \mathrm{t}$ cement can be saved by using green porous sponge ecological concrete, 298.685 yuan was saved, and $307.09 \mathrm{~kg} \mathrm{CO}$ emissions were reduced.

\section{Conclusions}

(1) Through the test, it was found that after adding different sponge particle contents with the same grain size to the green ecological concrete porous sponge, the compressive strength of green porous sponge ecological concrete increased with the increase of the sponge additive amount, but when it increased to a certain degree, the strength of the concrete reduced with the increase of the amount of sponge. The optimal admixture of the sponge was $0.9 \%$. Based on the optimal admixture of sponge, the compressive strength of the specimens peaked at the $12 \%$ admixture of mineral powder and its compressive strength is $31.1 \mathrm{MPa}$, while the "Specification for Design of Highway Cement Concrete Pavement "(JTG40-2011) requires that the compressive strength of highway cement concrete pavement is more than $25 \mathrm{MPa}$, so this concrete has enough strength.

(2) The water-retaining property of green porous sponge ecological concrete is more than twice as ordinary concrete, and its cooling performance and water permeability are also better than those of ordinary concrete. As the concrete pavement material, its water retention capacity is $6.96 \mathrm{~kg} / \mathrm{m}^{2}$; the velocity of water permeability is $1.78 \mathrm{~kg} / \mathrm{s} / \mathrm{m}^{2}$, due to the water blocking affection of the internal sponge with porous concrete, its water evaporation is smaller than ordinary concrete, it can help to reduce the temperature of the pavement.

(3) The $\mathrm{CO}_{2}$ emissions of each ton of cement are about $1.53 \mathrm{~g} / \mathrm{t}$, while compared with ordinary concrete, the green porous sponge ecological concrete greatly reduced the cement content and $\mathrm{CO}_{2}$ emissions, so it is very environmentally friendly and economical.

To sum up, the green porous sponge ecological concrete has a good engineering performance, and it can provide help for the infrastructure construction of sponge cities and play a guiding significance to promote the construction of resource-conserving and environment-friendly cities. Meanwhile, it also gives play to great social and economic effects in energy conservation and environmental protection and ecological construction, and it can be better applied in the concrete pavement design and ecological purification system in sponge city construction, so it will become the main environmental protection material in the construction of "sponge cities."

\section{Data Availability}

All the data included in this study are available upon request by contact with the corresponding author.

\section{Conflicts of Interest}

The authors declare that they have no conflicts of interest.

\section{Acknowledgments}

This work was funded by Advantage Technology Innovation Team of Jiangxi Province (Grant no. 20171BCB24012), National Natural Science Foundation of China (Grant no. 51869012), and Jiangxi Youth Science Foundation (Grant no. 20171BAB216042).

\section{References}

[1] Z. Xu, Research and Analysis on Causes of Heat Island Effect, Dalian University of Technology, Dalian, China, 2003.

[2] R. Sharma, P. Lolita, K. Maya, and P. Bhattacharya, "Assessing urban heat Islands and thermal comfort in Noida City using geospatial technology," Urban Climate, vol. 35, pp. 1-15, 2021.

[3] F. Aram, E. Solgi, E. Higueras Garcia, and A. Mosavi, "Urban heat resilience at the time of global warming: evaluating the impact of the urban parks on outdoor thermal comfort," Environmental Sciences Europe, vol. 32, no. 1, pp. 1-15, 2020.

[4] M. Das and A. Das, "Exploring the pattern of outdoor thermal comfort (OTC) in a tropical planning region of Eastern India during summer," Urban Climate, vol. 34, pp. 1-18, 2020.

[5] S. Sun, J. Zhai, Y. Li et al., "Urban waterlogging risk assessment in well-developed region of Eastern China," Physics and Chemistry of the Earth, vol. 115, pp. 1-8, 2020.

[6] L. Yao and T. Hu, "Research progress on urban waterlogging disaster simulation and disaster risk assessment," Geographic Information World, vol. 6, pp. 42-49, 2017.

[7] P. Chen, J. Zhang, Y. Sun, and X. Liu, "Wargame simulation theory and evaluation method for emergency evacuation of residents from urban waterlogging disaster area," International Journal of Environmental Research and Public Health, vol. 13, no. 12, pp. 1260-1293, 2016.

[8] C. He, Construction and Application of Sponge City Evaluation System, Southeast University, Nanjing, China, 2017.

[9] L. Wang, Calculation of $\mathrm{CO}_{2}$ Emission of Cement Manufacturing Enterprises, China Cement, Beijing, China, 2009.

[10] W. Shen, Y. Liu, M. Wu et al., "Ecological carbonated steel slag pervious concrete prepared as a key material of sponge city," Journal of Cleaner Production, vol. 256, Article ID 120244, 2020.

[11] L. Qian, F. Wang, Y. Yang et al., "Comprehensive performance evaluation of LID practices for the sponge city construction: a case study in Guangxi, China," Journal of Environmental Management, vol. 231, pp. 10-20, 2019.

[12] M. Randall, F. Sun, Y. Zhang, and M. B. Jensen, "Evaluating sponge city volume capture ratio at the catchment scale using 
SWMM," Journal of Environmental Management, vol. 246, pp. 745-757, 2019.

[13] Y. Zhou and D. Cao, "Application of recycaled waste aggregate in concrete," New Building Materials, vol. 47, no. 4, pp. 31-33, 2020.

[14] Y. Wang and Y. Xia, "Research on the influence of different water-absorptivity sand on performance of concrete," Traffic Engineering and National Defense Technology, vol. 14, no. 4, pp. 58-61, 2016.

[15] T. S. Nguyen and T. S. Nguyen, "A study on eco-concrete incorporating fly ash and blast furnace slag in construction in Vietnam," Applied Mechanics and Materials, vol. 897, pp. 98-105, 2020.

[16] G. Zaid, Y. Shao, and S. Zhang, "Performance of eco-concrete made from waste-derived eco-cement," Journal of Cleaner Production, vol. 289, pp. 145-158, 2020.

[17] Y. Deng, "Application of ecological concrete on Levee engineering," Helongjiang Hydraulic Science and Tecnology, vol. 48, pp. 152-155, 2020.

[18] F. Liu and F. Xie, "Exploration on the application of volcanic rock ecological concrete in ecological reservoir slope protection," Water Power, vol. 46, pp. 61-64, 2020.

[19] L. Nie, "Research on plant compatibility and biological characteristics of greening concrete," Master's Degree thesis, Fujian Agriculture and Forestry University, Fuzhou, China, 2008.

[20] M. Giavind and C. Munch-Petersen, "Green concretein Denmark," Structural Concrete, vol. 3, pp. 19-25, 2000.

[21] C. Meyer, "The greening of the concrete industry," Cement \& Concrete Composites, vol. 31, pp. 601-605, 2009.

[22] Y. Xu and F. Chena, "Effects of concrete content in vegetation concrete matrix on seed germination and seeding establishment of cynodon dactylon," Procedia Engineering, vol. 28, pp. 105-109, 2012.

[23] L. Wang, M. Jin, Y. Wu, Y. Zhou, and S. Tang, "Hydration, shrinkage, pore structure and fractal dimension of silica fume modified low heat Portland cement-based materials," Construction and Building Materials, vol. 272, pp. 1-13, 2021.

[24] L. Wang, R. Luo, W. Zhang, M. Jin, and S. Tang, "Effects of fineness and content of phosphorus slag on cement hydration, permeability, pore structure and fractal dimension of concrete," Fractals, vol. 29, no. 2, pp. 1-18, 2021.

[25] J. Fang, L. Zhao, and J. Shi, "Frost resistance and pore structure of concrete incorporated with rubber aggregates and nano-SiO ${ }_{2}, "$ Materials, vol. 14, no. 5, p. 1170, 2021.

[26] M. Yue Kon and L. Hsing Chou, "The eco-concrete with the papermaking sludge," Applied Mechanics and Materials, vol. 670-671, pp. 454-457, 2014.

[27] L. Wang, F. Guo, H. Yang, Y. Wang, and S. Tang, "Comparison of fly ash, PVA fiber, $\mathrm{MgO}$ and shrinkage-reducing admixture on the frost resistance of face slab concrete via pore structural and fractal analysis," Fractals, vol. 29, no. 2, pp. 1-18, 2021.

[28] G. Zhang, X. Li, C. Li, and Z. Li, "Pore structure of concrete under dry condition," Jounal of Northwest A \& F University, vol. 49, no. 1, pp. 136-142, 2021.

[29] L. Wang, T. He, Y. Zhou et al., "The influence of fiber type and length on the cracking resistance, durability and pore structure of face slab concrete," Construction and Building Materials, vol. 282, pp. 1-18, 2021.

[30] X. L. Du and L. Jin, "Research on the influence of pores and micro-cracks on the macro--mechanical properties of concrete," Engineering Mechanics, vol. 29, no. 8, pp. 101-107, 2012.
[31] J. Q. Jia, Y. L. Hu, D. L. Wang et al., "Effects of porosity on the compressive strength of concrete," Concrete, vol. 10, pp. 5659, 2015.

[32] C. F. Chen, T. Xu, M. Heap et al., "Modeling of the influence of pore size and porosity on strength characteristics of volcani crock," Journal of Northeastern University (Natural Science), vol. 38, no. 5, pp. 725-729, 2017.

[33] L. Wang, M. Jin, F. Guo, Y. Wang, and S. Tang, "Pore structural and fractal analysis of the influence of fly ash and silica fume on the mechanical property and abrasion resistance of concrete," Fractals, vol. 29, no. 2, pp. 1-18, 2021. 